\title{
Do "buraco" ao atrativo turístico: uma sociologia da ressignificação do rural
}

\author{
From the "hole" to the tourist attractive: a sociology of \\ rural resignification
}

\author{
Rodrigo Constante Martins ${ }^{1}$ (D) e Gabriel Alarcon Madureira ${ }^{1}$
}

\begin{abstract}
Resumo: O objetivo do artigo é discutir as transformações contemporâneas do rural a partir dos fenômenos da ressignificação da natureza e da questão ambiental. O trabalho toma como base um estudo de caso sobre as representações da natureza no município de Brotas, situado na região central do estado de São Paulo. Neste município, a afinidade eletiva entre profissionalização do turismo de aventura, questão ambiental e ressignificação discursiva do rural foi responsável por um importante movimento de transformação da localidade entre 1990 e a primeira década do século XXI. O tema específico a ser discutido neste caso será a criação de um "objeto de natureza" que passou a caracterizar o rural no município - a saber, as cachoeiras, anteriormente estigmatizadas como "buracos" e posteriormente transformadas em atrativos ambientais dotados de valor econômico.
\end{abstract}

Palavras-chave: ruralidades e meio ambiente, ressignificação do rural, turismo rural e meio ambiente, novas ruralidades.

Abstract: This article aims to discuss the contemporary transformations of the rural based on the resignification phenomenon of nature and the environment. The article will be based on a case study about the representations of nature in Brotas, city located in the central region of São Paulo state. In this city, the elective affinity between the professionalization of adventure tourism, environmental issues and the discursive resignification of the rural was responsible for an important transformation of the locality from the 1990s to the first decade of the 21st century. The specific theme to be discussed in this case is the creation of an "object of nature" which has begun to characterize the rural in Brotas - namely the waterfalls, that previously was stigmatized as "holes", and later transformed into environmental attractions endowed with economic value.

Key-words: ruralities and environment, rural resignification, rural tourism and environment, new ruralities.

Classificação JEL: Q56, R14, Z13

Data de submissão: 23 de setembro de 2017. Data de aceite: 18 de junho de 2018.

1. Universidade Federal de São Carlos (UFSCar), São Carlos (SP), Brasil. E-mails: constantemartins@gmail.com; kgabmadk@hotmail.com 


\section{Introdução}

O debate sobre as ruralidades contemporâneas tem sido largamente marcado pela emergência da questão ambiental. Do ponto de vista da teoria social, uma das estratégias de abordagem desta temática passa pelas discussões sobre os desencaixes espaço-temporais das sociedades modernas, que teriam redefinido as relações entre os mundos rural e urbano. Diversos estudos têm recorrido ao suporte analítico da teoria da estruturação para investigar as transformações das ruralidades em diferentes territórios, mantendo diálogo mais amplo com os deslocamentos cognitivos que qualificam os novos contornos da modernidade ocidental, seja nos termos de sua delimitação "ecológica" ou "reflexiva" (Alphandéry \& Billaud, 2009; Jean, 2002).

Em consonância com tal debate, este artigo problematiza as transformações do rural como expressão de mudanças cognitivas mais profundas, que se revelam, dentre outros, pela criação de novos "objetos de natureza". Seu objetivo é discutir tais transformações a partir da ressignificação da natureza e da questão ambiental. Para tanto, o trabalho toma como base um estudo de caso sobre as representações do espaço rural no município de Brotas, situado na região central do estado de São Paulo. Neste município, a afinidade eletiva entre profissionalização do turismo de aventura, questão ambiental e ressignificação discursiva do rural foi responsável por um importante movimento de transformação da localidade entre 1990 e a primeira década do século XXI. O tema específico a ser discutido neste caso será a criação de um "objeto de natureza" que passou a caracterizar o rural no município - a saber, as cachoeiras, anteriormente estigmatizadas como "buracos" e posteriormente transformadas em atrativos ambientais dotados de valor econômico.

$\mathrm{O}$ artigo está divido em oito tópicos. Após esta introdução, nos tópicos dois e três são apresentados, respectivamente, a problematização teórica que sustenta a análise sociológica sobre a ressignificação da natureza e do rural em Brotas e os procedimentos metodológicos do estudo de caso. No quarto tópico é realizada uma breve apresentação do espaço social municipal, com destaque para a emergência dos agentes e instituições que começam a pautar a questão ambiental no município na década de 1990. Na seção cinco são discutidas as representações sociais da paisagem local (das cachoeiras e corredeiras, em particular). A ressignificação da paisagem rural no plano do agenciamento das práticas é analisada nos tópicos seis e sete. Na seção final são elencadas as considerações finais mais significativas sobre o estudo de caso e sobre o potencial do suporte analítico aqui empregado.

\section{Nota teórica}

No propósito de discutir a ressignificação da natureza em contextos contemporâneos de ruralidade, este trabalho parte do pressuposto de que processos sociais complexos revelam diferentes camadas de relações e interações entre os agentes. E não se supõe aqui que as diferentes 
camadas de relações que marcam a ressignificação da natureza possam ser interpretadas sob a perspectiva de um recorte analítico fixo e monocromático. Desde este ponto de partida, o artigo em tela mobiliza esforços analíticos que colocarão em evidência diferentes camadas de fenômenos e relações concernentes ao rural contemporâneo.

$\mathrm{Na}$ realização das etapas de campo do estudo de caso, o primeiro referencial analítico adotado foi a teoria da estruturação de Anthony Giddens, com vistas a problematizar o agenciamento das práticas dos agentes do lugar. Para tanto, foram trabalhados os três conceitos fundamentais da teoria da estruturação do autor, quais sejam: estrutura, agência e sistema social.

Sabidamente, na obra de Giddens (1989), a estrutura é definida como conjunto de regras e recursos que são mobilizados pelos agentes nos contextos de interação nos quais estes encontram-se situados. Esta estrutura não é fixa e nem objetiva, existindo essencialmente no plano cognitivo, enquanto traços de memória do agente reflexivo e cognoscente. A agência, por sua vez, é a capacidade individual do agente em mobilizar recursivamente as regras e recursos da estrutura, visando alcançar resultados por ele pretendidos. Desta sorte, as ações individuais nos quadros de interação estão vinculadas às possibilidades de agenciamento e à capacidade de mobilizar os recursos disponíveis, criando um quadro situacional variável em relação às características dos encontros, posto que os recursos envolvidos são sempre relacionais e posicionais.

Essa equação dinâmica, dialógica e reflexiva que se estabelece entre agência e recursos - essa característica fluída e relacional da estruturação - opera justamente na vida cotidiana dos indivíduos, os quais reproduzem e transformam tais relações. É no plano da rotina que a escolha de certos recursos para a ação se torna naturalizada, forjando, assim, a estabilidade de uma miríade de relações sociais no tempo e no espaço. De fato, é esta padronização das relações sociais ao longo do tempo-espaço que forma um sistema social específico no âmbito da teoria da estruturação.

Considera-se, portanto, que as regras e recursos não existem concretamente nos sistemas, mas, sim, como estrutura. E a estrutura não se objetiva e não existe em lugar algum, mas é operacionalizada pelas ações recursivas dos agentes, pela constituição da sociedade por meio do monitoramento reflexivo da ação.
Em síntese, o sistema social é fruto da padronização e estabilização de um processo de estruturação resultante de disputas de leituras de mundo, de construção de projetos, de mobilização de regras e recursos em prol de interesses individuais, coletivos e difusos, em prol de ações desempenhas por indivíduos e instituições. É sob tal perspectiva, por exemplo, que Giddens (2009) aborda a questão ambiental como recurso mobilizado em discursos de governos e instituições multilaterais, mas sem revelar-se como efetiva propriedade estrutural no agenciamento das práticas sociais rotinizadas neste início de século ${ }^{1}$.

Essa retomada sintética de conceitos elementares da teoria da estruturação é pertinente para compreendermos justamente as ruralidades como sistemas sociais específicos. Mais do que isso, conforme aponta Carneiro (2012; 2008), pesquisas contemporâneas têm mostrado que de fato a dualidade entre campo e cidade - rural e urbano - apresenta-se difusa e não mais nítida, constituindo um marco epistemológico fronteiriço da sociologia, exigindo assim abordagens multidisciplinares capazes de observar o rural como categoria de pensamento suscetível de ser utilizada recursivamente por agentes e grupos em interação e disputas sociais. Neste contexto, a questão fundamental a ser destacada são os recursos mobilizados no processo de ressignificação dos espaços rurais, cuja maior especificidade, como salienta Jollivet (1998), reside na irrupção da questão ambiental.

Em diálogo com o suporte teórico da teoria da estruturação, Jean (2002) argumenta que as mudanças operadas no plano dos espaços rurais podem ser compreendidas como uma recomposição dos sistemas sociais a partir de indicadores determinados, ligados às formas de geração de renda, de constituição de identidades, atividades profissionais, escolaridade, instrumentos de comunicação, turismo pluriativo, etc. Diferentemente da afirmação já clássica de Kayser (1989) acerca do renascimento do rural, Jean destaca sua diversificação desde as duas últimas décadas do século XX, constituindo, assim, uma pluralidade de sistemas sociais, vinculados a processos específicos de valorização ou ressignificação

1 Sem embargo, a publicação de The politics of climate change por Giddens em 2009 marca sua reflexão mais detida sobre a temática ambiental. Para uma análise desta obra no contexto da teoria da estruturação, ver Martins (2011). Para um estudo dos diferentes momentos em que a questão ambiental aparece na obra do sociólogo inglês antes da publicação da obra supracitada, ver Lenzi (2006). 
da agricultura e da natureza, por exemplo. Por isso, no lugar do "renascimento", Jean prefere enfatizar a pluralidade dos sistemas sociais - ou seja, destaca as "ruralidades" que concreta e simbolicamente estruturam as relações campo-cidade.

Também em diálogo com a teoria da estruturação, Long \& Ploeg (2011) ressaltam o potencial analítico da noção de agência para se problematizar as transformações destes sistemas rurais. Mesmo enfatizando a importância dos princípios de cognoscibilidade e capacidade para a noção de agência, os autores destacam a relevância da tradução cultural destes princípios. Os seja, a cognoscibilidade e capacidade de agenciamento não são atributos universais, mas, sim, habilidades construídas histórica e culturalmente. No mundo rural, a diversidade resultante destas construções afeta decisivamente o gerenciamento das relações interpessoais e os tipos de controle e luta classificatória que os atores podem produzir sobre o próprio ambiente natural.

Sob a perspectiva desta diversidade do rural e da irrupção da questão ambiental em sua ressignificação, questões empíricas do estudo de caso em tela demandaram esforços analíticos complementares à teoria da estruturação. Dentre estas questões, está a experiência empírica da passagem dos recursos naturais à condição de ativos monetários nas propriedades fundiárias locais. Conforme se verá adiante, esta ressignificação revelou as especificidades históricas das disputas em torno do imaginário local sobre o ambiente e sobre aquilo que a literatura especializada chamará de valoração econômica da natureza ${ }^{2}$. Para a interpretação desta valoração neste estudo adotou-se a hipótese desenvolvida por Boltanski \& Esquerre (2017) acerca dos modos de circulação dos objetos e justificação de seus valores. Isto é, se considerará que, em alguns contextos, os modos de circulação e definição dos valores das mercadorias estão submetidos sobretudo a relações linguísticas, que são mobilizadas via imperativos de justificação. Desde esta perspectiva, será interpretado como o suporte linguístico empreendido na valoração econômica dos atributos naturais de Brotas permitiu a ressignificação dos então "buracos" de descarte aos atrativos turísticos que, na atualidade, marcam a economia regional.

2 Não está entre os objetivos deste artigo discutir os princípios conceituais da valoração econômica dos recursos naturais. Para uma síntese da compreensão da valoração econômica no espectro do mercado dos enunciados ambientais contemporâneos, ver Martins (2015).
Por fim, no propósito de dar ênfase às dimensões locais do referido processo de ressignificação, o contexto e a territorialidade rural serão abordados na perspectiva da noção de milieu econômico, tal como proposta por Martins (2014). Esta noção, inspirada na obra de Weber (1982), é resgatada e atualizada no debate contemporâneo do rural para enfatizar um olhar analítico histórico territorial, voltado às particularidades que também fazem o que comumente se define como economia - tais como a história política local, as características culturais, os capitais de prestígio social e os atributos ambientais. Conforme enfatiza Martins, a noção de milieu econômico nos estudos rurais e socioambientais permite escapar dos determinismos econômico e geográfico, dando lugar ao princípio da multicausalidade na explicação dos fenômenos sociais.

\section{Operacionalização metodológica}

É impossível não lembrar de Brotas quanto entramos no segmento ecoturismo (São Paulo, n. d., p. 16). É assim que a publicação Turismo em São Paulo, editada pela parceria Embratur e governo do estado de São Paulo, apresenta o município de Brotas. Também chamada de capital brasileira do turismo de aventura, a cidade está localizada na região central do estado de São Paulo (a $235 \mathrm{~km}$ da capital) e tem pouco mais de 20 mil habitantes. Está sobre a área de afloramento do Aquífero Guarani e integra a Área de Proteção Ambiental Corumbataí-Tejupa (Brotas, 2011).

O município de Brotas foi escolhido para a realização deste estudo justamente por ser um espaço rural que, desde o início da década de 1990, vem sendo ressignificado por múltiplas percepções da questão ambiental. $\mathrm{O}$ rio Jacaré-Pepira, que corta o município, tem relevância determinante não apenas para a paisagem local - sendo referencial para o estabelecimento de regionalizações e bairros - mas também emergiu como eixo de socialização, lazer e identidade para diversas faixas etárias da população. A atividade de "descer" o rio com boias improvisadas de caminhão; a "aventura" de realizar trilhas na mata e de descobrir atrativos e belezas naturais e o hábito de nadar em trechos específicos das corredeiras se tornaram práticas que identificam e distinguem o território local no contexto do rural paulista. Além disso, nos anos 
1980 começaram as primeiras iniciativas de construção de consórcios municipais locais com o objetivo de proteger os recursos naturais da região: fauna e flora ricas, cachoeiras e corredeiras em abundância, minas e nascentes variadas, e o rio Jacaré-Pepira limpo e preservado. Foi justamente essa configuração específica que permeou o entrelaçamento entre as atividades de aventura, o usufruto da natureza e a consciência de preservação ambiental na localidade.

Para a operacionalização desta investigação sobre a ressignificação do rural e da natureza no plano local, optou-se pelo desenvolvimento de um estudo de caso qualitativo de caráter exploratório. O estudo foi realizado entre 2012 e 2013. Foram aplicados questionários de caracterização socioeconômica e realizadas entrevistas semiestruturadas a partir da composição de uma rede de interlocutores, com o emprego da técnica de amostragem de propósito, baseada em Patton (2002). Esta técnica permitiu a seleção dos entrevistados a partir da densidade informacional do agente ante os propósitos da pesquisa $^{3}$. Também foi realizada observação direta dos encontros sociais nas práticas de turismo com registro em diários de campo, bem como o acompanhamento de reuniões do Conselho Municipal de Defesa do Meio Ambiente (Condema) e do Conselho Municipal de Turismo (Comtur). Por fim, o estudo contou ainda com levantamento documental junto ao Condema, Comtur, Prefeitura Municipal de Brotas, Conselho Municipal de Desenvolvimento Rural, Secretaria do Meio Ambiente, Secretaria da Agricultura e OnG Movimento Rio Vivo.

O conjunto de dados e informações reunidos com tais procedimentos foram sistematizados sob a perspectiva do milieu econômico (Martins, 2014) e interpretados à luz do suporte conceitual da teoria da estruturação (Giddens 1989; 2002). Em particular, buscou-se identificar neste material as propriedades estruturais envolvidas nas práticas de interação e sua mobilização como regras e recursos pelos agentes sociais. As representações de valoração econômica dos atributos ambientais, quando mobilizadas pelos agentes, foram interpretadas na

Cumpre destacar que a amostragem de propósito (proposeful sampling) também se revelou mais adequada considerando o escopo teórico deste estudo. Sem embargo, na medida em que se empreende uma análise sociológica a partir da teoria da estruturação - e, consequentemente, são considerados valores, conceitos e discursos como recursos fluídos mobilizados na contextualidade da interação social -, a possibilidade de repetição/saturação das informações perde relevância ante à riqueza da diversidade discursiva. perspectiva da justificação moral (Boltanski \& Esquerre, 2017). Por fim, a ruralidade, concebida como sistema social (Jean, 1997, 2002), pôde ser problematizada em termos tanto de território como de representação simbólica e construção identitária (Silva \& Leal, 2015).

\section{O espaço social municipal}

Como bem sugere Bourdieu (2001), espaço físico e espaço social são representações diferentes e dificilmente coincidem. Notadamente, o espaço social, estruturado em distâncias simbólicas, comumente escapa das fronteiras fisiográficas ou do ordenamento político dos territórios. No caso do turismo rural de Brotas, contudo, o espaço social nos é revelado, desde a década de 1990, em um arranjo bastante particular de propriedades e agentes nas disputas em torno das formas de uso e acesso aos recursos naturais locais, de tal modo que, neste caso, pode-se considerar que o espaço social se apropria do espaço físico municipal e o retraduz como espaço social reificado.

No início dos anos 1990, a cidade de Brotas estava imersa em um contexto econômico caracterizado por disputas entre as administrações municipais com o objetivo de atrair atividades industriais capazes de gerar emprego e renda para a localidade. Em vista disso, uma empresa de grande porte, especializada em tratamento de couro cru - uma indústria de curtume - proveniente da região de Campinas, propôs instalar-se no município e fazer uso do rio Jacaré-Pepira para o rejeito de resíduos inerentes à atividade. Diante da ameaça ambiental, um grupo da população local fundou o Movimento Rio Vivo com vistas a proteger o rio Jacaré-Pepira, reagindo contrariamente à instalação da indústria de curtume na cidade (Madureira, 2013).

A alternativa à implantação da indústria de curtume caracterizou-se justamente pela organização do município como destino baseado na oferta de práticas recreativas de aventura e fortemente vinculado ao ecoturismo. Desde 1993, após a abertura da primeira operadora de turismo de aventura, Brotas vem sendo perpassada por movimentos de expansão e contração desse tipo de empreendimento, os quais são essencialmente também processos contínuos de profissionalização, ressignificação e de pluriatividade no âmbito do município. 
Atualmente, Brotas é um dos principais destinos turísticos do estado de São Paulo no que tange à oferta de práticas relativas à aventura em ambientes naturais, com uma destacada estrutura organizacional para o turismo - através da Abrotur (Associação das Empresas de Turismo de Aventura de Brotas e Região) e de grandes agências operadoras. O município também registra um importante aparato de gestão ambiental local, com atuações conjuntas entre Secretaria do Meio Ambiente, Secretaria do Turismo, Conselho Municipal de Desenvolvimento Rural e Comtur. Esta estrutura pública, articulada às entidades representativas do setor, conformou em Brotas tanto um ambiente institucional e político quanto valores simbólicos favoráveis ao desenvolvimento do chamado "turismo de natureza" - modalidade que vem ressignificando o tradicional turismo rural-agrícola em várias partes do mundo (Carneiro \& Teixeira, 2012).

Neste contexto, pode-se considerar que o cerne do processo de transformação de Brotas, enquanto espaço rural desde a década de 1990, se baseia na preservação ambiental, na valoração simbólica dos recursos naturais e no investimento público e privado em novas modalidades de turismo, sejam estes definidos como rural, de aventura ou de natureza ${ }^{4}$.

\section{Do "buraco" ao atrativo turístico}

O processo de ressignificação dos recursos naturais do município pode ser compreendido a partir da mobilização recursiva das múltiplas percepções cognitivas da questão ambiental, colocando-se em pauta o processo de privatização do ambiente. Mas, antes deste processo, o uso que a população local fazia da natureza era sintomático acerca das representações então criadas sobre aquele espaço rural. O relevo acidentado da região, somado à riqueza de seus cursos d'água, formavam efetivas

\footnotetext{
O debate sobre as diferentes formas de mobilização da questão ambiental no escopo das novas estratégias de desenvolvimento rural segue relevante na literatura internacional. O caso europeu, emblemático desde a década de 1990, tem nas políticas agroambientais praticadas no âmbito do programa Leader (Ligação Entre Ações de Desenvolvimento da Economia Rural) uma expressão importante dos rumos do debate em termos de intervenção pública. A propósito das políticas agroambientais desenvolvidas na primeira fase do pograma Leader, ver Martins (2005). Para as intervenções do programa na área específica de turismo rural, ver McAreaveu \& McDonagh (2011).
}

vias de descarte de resíduos de toda ordem. Segundo um conjunto de informantes, os atrativos turísticos de hoje - principalmente as cachoeiras, o grande símbolo do turismo de aventura baseado em práticas verticais eram desprezados na classificação cotidiana do ambiente. Eis o que uma das integrantes do Movimento Rio Vivo e ex-secretária do Meio Ambiente expôs sobre o tema:

Vinha o Rio Vivo falando que a gente tinha condição de trabalhar, de ganhar dinheiro com as matas. Aívocê ia falar isso para o produtor, para o cara do sítio que tinha cachoeira e ele falava: "larga a mão, aquele buraco, o que vocês vão fazer lá?" Aquele buraco lá são as cachoeiras. Eàs vezes as pessoas iam lá na cachoeira, aquelas mais fáceis de se chegar, e iam até lá só pra brincar na água, no riozinho. (Depoimento concedido em abril de 2012)

O depoimento aponta um termo fundamental para se compreender a concepção dos atrativos ambientais antes e depois dos processos de ressignificação dos recursos territoriais desencadeados pela profissionalização do turismo e por uma nova percepção cognitiva acerca da questão ambiental. Ao longo das localidades brotenses (no interior de cada sítio), as cachoeiras e as corredeiras eram consideradas apenas coadjuvantes na função específica da propriedade, geralmente voltada para a pecuária ou cultivo de laranja, cana-de-açúcar ou eucalipto. As características geográficas e paisagísticas da propriedade eram classificadas como "buracos", verdadeiros empecilhos para o desempenho da atividade produtiva principal. Posteriormente, se transformariam justamente no ativo de maior valor e distinção de uma propriedade após os anos 1990 - período de explosão do turismo e da nova concepção e utilização recursiva da natureza.

Segundo outro informante, condutor de rafting, guarda municipal, e fundador da ABCT (Associação Brotense dos Condutores de Turismo):

Alguns proprietários comentavam com a gente: "o que
vocês querem com um buraco desse? É um buraco,
o que vocês querem com esse buraco?". Sabe o que
eles faziam com esse buraco? Morria um animal e
eles jogavam lá, cair dentro da cachoeira [...] Diziam:
"por que você vai deixar esse animal ficar fedendo?
Próximo de alguém ou da casa? Vamos jogar na
cachoeira". Arrastavam, jogavam na cachoeira,
a água levava aquilo, se desfazia com a água...
Esse era o pensamento. (Depoimento concedido em
julho de 2012) 
Diante do fato da então cachoeira, considerada "buraco" para o descarte de animais, ter se tornado objeto de valor econômico revestido por um discurso de proteção ao meio ambiente, torna-se relevante compreender, a partir das interações sociais, as representações dos fatores ambientais que foram mobilizadas recursivamente neste processo de ressignificação do espaço. Isto é, sob a perspectiva da teoria da estruturação de Giddens (1989), torna-se relevante o desvendamento do modo como a questão ecológica se torna recurso de mobilização reflexiva para novas práticas e agenciamentos - dentre os quais se inclui a valoração econômica da natureza ressignificada.

Na Figura 1, abaixo, pode-se observar, através da cachoeira Roseira, localizada em sítio particular transformado em empreendimento turístico, como o "buraco" adquiriu infraestrutura adequada para o turismo, não só com a construção de passarelas devidamente sinalizadas, mas com a sua valoração ambiental, já que o sítio cobra entrada dos visitantes que desejam passar o dia no espaço, que dispõe ainda de um mirante, um restaurante local, trilhas e um viveiro de animais.

$\mathrm{Na}$ foto observa-se um espaço com infraestrutura baseada nos pressupostos de segurança e perícia obrigatórios no turismo de aventura. É possível observar a presença de uma passarela com piso antiderrapante e corrimão, placa de sinalização e uma corda ao fundo, utilizada para as atividades de rapel. Este sítio é um importante exemplo do processo que ocorreu na maior parte das propriedades de Brotas com atrativos ambientais: a transformação do "buraco" e sua ressignificação acionada

Figura 1. Cachoeira da Roseira, município de Brotas.

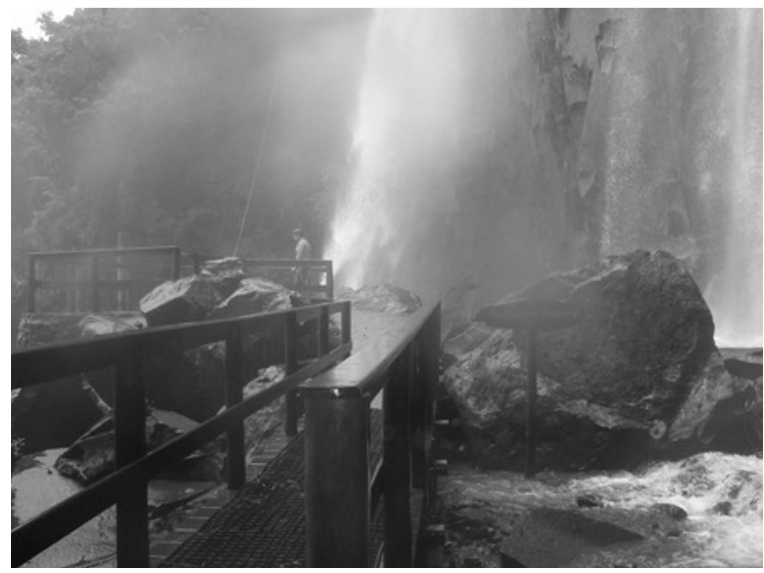

Fonte: Pesquisa de campo (fotodocumentação), abril de 2012. pela questão ambiental, passando a operar como fonte de valor. Como aponta o presidente da OnG Movimento Rio Vivo:

Um proprietário estava me contando que, hoje, a propriedade toda dele não dá o lucro que o "buraco" dá. Ele chamava de "buraco" porque era um lugar que de vez em quando caía bezerro e ele perdia bezerro porque não tinha como descer lá para trazer o bezerro de volta. (Depoimento concedido em abril de 2012)

A rigor, o presidente da OnG refere-se a um conjunto de percepções acerca do meio ambiente e da natureza partilhadas pelos proprietários de fazendas ou de sítios na localidade, os quais assumem que "o buraco da propriedade hoje dá mais lucro do que a fazenda inteira". Os "buracos", tão característicos do município de Brotas, se tornaram mais do que atrativos ambientais complementares às atividades de geração de renda de algumas propriedades: se transformaram muitas vezes na atividade principal, fato que justificou a instalação de restaurantes, lojas de artesanatos, hotéis etc. Em síntese, a ressignificação da natureza emerge como eixo de transformação do contexto de ruralidade que se desvincula de suas características tradicionais e se torna eminentemente pluriativo (Rodrigues, 2012) e socioambiental (Brandenburg, 2010).

Esta transformação, com repercussões econômicas importantes, se consolidou ao longo do tempo por que se baseou em novas estratégias recursivas de mobilização da questão ambiental no território e na relação deste com as representações urbanas das amenidades ambientais. Assim, o que a princípio poderia ser interpretado simplesmente como nova frente de empreendedorismo rural, se revela como realidade mais complexa na medida em que há um novo modo de agenciamento das práticas sociais que remete a uma modalidade de reflexividade ecológica externa ao território. Conforme se discutirá a seguir, a natureza local - então "buraco" - é convertida em meio ambiente e é recursivamente acionada no contexto das demandas sociais da moderna questão ambiental.

\section{A natureza contextualizada}

De acordo com o fundador da primeira operadora de turismo de aventura de Brotas, a contextualização dos "buracos" nas propriedades rurais do município 
efetivamente assumiu novo significado com a perspectiva de sua valoração econômica.

Isso passou a ser valorizado em Brotas pelo produtor rural, ele teve essa noção, com o desenvolvimento do turismo, ecoturismo. O dono de cachoeira passou a respeitar a cachoeira, aceitou até a plantar árvores porque passou a ganhar dinheiro com aquela cachoeira. Até então aquela furna era um cemitério de carcaça, tanto de trator, de equipamento, como de bicho. Jogavam tudo no "buraco". Hoje não. Dependendo da propriedade rural, o buraco hoje é a principal arrecadação. (Depoimento concedido em maio de 2012)

Na visão dos proprietários, jogar no "buraco", no espaço da cachoeira, significava livrar-se do rejeito e deixá-lo a cargo da água e do fluxo do rio, sem apresentar nenhum tipo de preocupação com a qualidade e preservação do recurso. Tal postura se transformou a partir do momento em que emergiu um contexto específico de revalorização da água - a profissionalização do turismo e a possibilidade de exploração econômica dos agora "ativos" ambientais. E esta revalorização - como todo valor, mais atrelado à ordem do acontecimento que do fato (Boltanski \& Esquerre, 2017) - teve sua justificação sustentada na causa (ou ordem de grandeza) ecológica. Outrossim, o processo de valoração ambiental propiciado por esta profissionalização do turismo de aventura em Brotas veio acompanhado de um movimento de estabelecimento de marcos mais rígidos no âmbito da propriedade privada dos espaços rurais. Se antes os bens naturais da localidade eram amplamente acessíveis à toda a população, no contexto da ressignificação do turismo rural no município os atrativos ambientais tornaram-se restritos e destinados a práticas específicas, agora então portadores de um meta-preço justificado não por sua produção ou pela ampla procura, mas, sim, por seu significado nos tempos da moderna crise ambiental.

A história do principal hotel fazenda do município está intimamente ligada à construção local da noção de valor econômico das amenidades ambientais. A partir do depoimento da proprietária do hotel fazenda, pode-se inferir que, na década de 1980, a valoração econômica da natureza não era um recurso integrado ao agenciamento das práticas sociais dos proprietários de terras em Brotas.

[sobre cobrar pelo acesso à cachoeira] Jamais, não se falava nisso, não se falava em cobrar. Aí teve uma situação que, acho que na década de 1980, quando muita gente queria vir na mina [ forma de nomeação da nascente d'água na propriedade], porque era um lugar legal. E aí o pessoal vinha e acabava deixando porteira aberta, entrava gado onde não podia e, se tinha roça de milho, catavam milho, passavam no pomar e catavam laranja... E meu pai já não gostava dessa história de deixar o povo ir na mina. Ele não queria mais. A gente mesmo pensava: "Será que vamos poder ir lá na mina? Vai ter muita gente?". (Depoimento concedido em junho de 2012)

No depoimento da empresária, observa-se a tendência ainda anterior à profissionalização do turismo, de "cercamento" das propriedades privadas de Brotas, pois os bens naturais sempre foram objeto de uso e de práticas recreativas pelos habitantes locais. A questão principal é que não havia contexto na década de 1980 para que a questão ambiental fosse mobilizada enquanto um recurso econômico e voltado para sua exploração e geração de renda. Ao contrário, as propriedades eram espaços privados de sociabilidade das famílias proprietárias, as quais utilizavam os atrativos ambientais para recreação de seu círculo social.

Segundo a empresária, a forma de sua família resolver o problema do uso indesejado da propriedade rural - conhecida amplamente no município pela existência da mina, nascente que dá origem ao nome do empreendimento - foi a instalação de um "cadeadão na porteira", ou seja, o impedimento ao livre acesso. Mais do que isso, a empresária ressalta a completude do cadeado: a proibição à circulação de pessoas estranhas e ao usufruto do bem natural, do nado e da pesca ${ }^{5}$.

Após o empreendimento turístico ganhar forma e surgirem as primeiras oportunidades em relação à exploração da propriedade rural, os mecanismos de privatização da natureza e dos espaços naturais se disseminaram em Brotas. A nova classificação dos rios que permeiam as propriedades, por exemplo, reflete desde então a questão ambiental em termos de recurso econômico e como nova fonte de renda para os proprietários rurais. Ou seja, neste milieu econômico, a partir da década de 1990, com a ressignificação da localidade, todo e qualquer aspecto geográfico-paisagístico da territorialidade transformou-se em potencial objeto de exploração turística, contribuindo para o desenho local do que Ellis (2000) adequadamente classificou como diversificação dos meios de vida no próprio grupo doméstico rural.

Sabidamente, o turismo baseado em recursos ambientais realizado em propriedades particulares revela um conjunto significativo de implicações para as diferentes formas de domínio da terra. A propósito deste tempo no debate internacional, ver Matilainen e Lähdesmäki (2014). 


\section{O nascimento do empreendimento da nascente}

É justamente este último empreendimento, um dos maiores e mais complexos estabelecimentos turísticos da região, que constitui o exemplo empírico mais evidente desse processo de ressignificação do turismo rural de Brotas a partir da natureza. Mantendo as bases analíticas da teoria da estruturação, será evidenciada para o caso deste empreendimento a utilização recursiva da questão ambiental na transformação do então "buraco" em atrativo turístico.

O nome do estabelecimento faz alusão à nascente que brota em meio a uma areia branca, feita de finíssimos grãos de quartzo, que produzem som característico quando friccionados. Segundo a empresária e administradora, a famosa nascente antes era chamada de mina e não possuía a valoração econômica e significação que tem hoje. Ao rememorar as práticas e representações de seu pai e de sua mãe acerca daquele espaço, a empresária expõe o longo processo de debates familiares dos quais resultou a valoração ambiental do sítio:

Queriam vir aqui por causa da nascente e da cachoeira e a gente não deixava. Meu pai achava que esse negócio de cobrar para ir nas casas, isso não estava certo. Que isso não podia ser. Ele dizia: "como que vai cobrar para as pessoas virem na casa da gente?". Pra ele era muito estranho. E ele não concordava. Mas os meninos lá da Mata d'entro querendo. Diziam: "Vamos levar o pessoal lá" e a gente nessa resistência. Mas nessa resistência a gente já estava achando que era uma coisa que poderia ser boa, estávamos pensando. Aí minha mãe, foi a grande que teve a ideia, ela falou "olha, é o seguinte, nós não precisamos cobrar para a pessoa entrar aqui, porque não tem mesmo muito sentido. Mas a gente cobra por alguma coisa que a gente vai dar, a gente faz um café, do jeito que o pessoal gosta, eles tomam caféaqui". Porque o pessoal vinha, nadava, brincava, subia e comia, porque dava fome. Ela falou: "vamos fazer aquilo que a gente sempre fez pra todo mundo, café, queijo, doces, tudo que tiver põe na mesa e cobra por isso, cobra porque estamos dando isso pra gente que não é de casa". Meu pai falou: "cobrar por isso, então pode ser", concordou. [...]Em 2000 veio o hotel. Era a mesma história, o pessoal vinha, comia, passeava na mina e falava assim "Não tem um lugar aqui pra gente ficar? O pessoal queria dormir por aqui", e assim foi.

A empresária destaca a relação entre o uso tradicional da propriedade em um contexto de ruralidade específico, vinculado à uma forma de compartilhamento e de abertura da propriedade, o qual se transforma a partir dos primeiros debates com "os meninos", justamente com os empreendedores pioneiros do turismo de aventura profissional em Brotas. Através do embate entre o patriarca e a matriarca da família, a administradora destaca o processo de renegociação de sentido da propriedade através da ressignificação do espaço rural e da questão ambiental em torno do município. E o agenciamento das práticas relacionadas com a criação dos novos objetos de natureza - tais como a nascente e a cachoeira - reverberam tensões também relacionadas com os perfis de gênero afeitos ao novo empreendedorismo rural ligado ao patrimônio ambiental. Com efeito, no caso de Brotas o envolvimento das mulheres no agenciamento de uma nova visão sobre o ambiente local parece se relacionar decisivamente com a resistência ao domínio material e aos valores da tradicional propriedade patriarcal. Mas, para além deste caso, convém destacar que as tensões de gênero no redimensionamento do mundo agrário são uma marca do rural contemporâneo, sobretudo no que concernente às chamadas novas empresas rurais (Wright \& Annes, 2014; Lunardi \& Souza, 2011). Conforme sugere estudo de Dieguez-Castrillon et al. (2012), a partir da realidade da Galizia (Espanha), as mulheres, mais do que os homens, respondem com maior disposição aos desafios da diversificação econômica no rural (em particular no que tange ao turismo rural), de tal sorte que esta variável de gênero, a depender do milieu econômico, em certos contextos, pode se sobrepor à origem social, familiar ou mesmo ao estímulo institucional nas mudanças do perfil de renda no campo.

$\mathrm{Na}$ análise do folder institucional do empreendimento (Figura 2) pode-se verificar empiricamente a ressemantização do espaço rural a partir da natureza. Em grande medida, como pôde-se acompanhar nos depoimentos nos agentes locais e se observa na imagem supra, esta ressemantização teve como suporte linguístico e imagético bases de justificação associadas aos imperativos ecológicos envolvidos no debate contemporâneo sobre o bem comum (Lafaye \& Thévenot, 1993) ${ }^{6}$. Em relevo, no mosaico de imagens encontrado nesse material de divulgação, destaca-se a mina como cartão postal da fazenda, local

6 A referência à noção de bem nesta abordagem dialoga com o empreendimento analítico de Boltanski e Thévenot (1991) acerca das grandezas de justificação recorrentes em contextos desacordo e disputa social. Inspirados neste empreendimento, Lafaye e Thévenot (1993) sugerem a constituição de um imperativo ecológico de justificação das práticas, crescentemente mobilizado como recurso pelos agentes envolvidos em situações específicas de disputas. 
Figura 2. Folder de hotel fazenda no município de Brotas (SP). Dezembro de 2012.
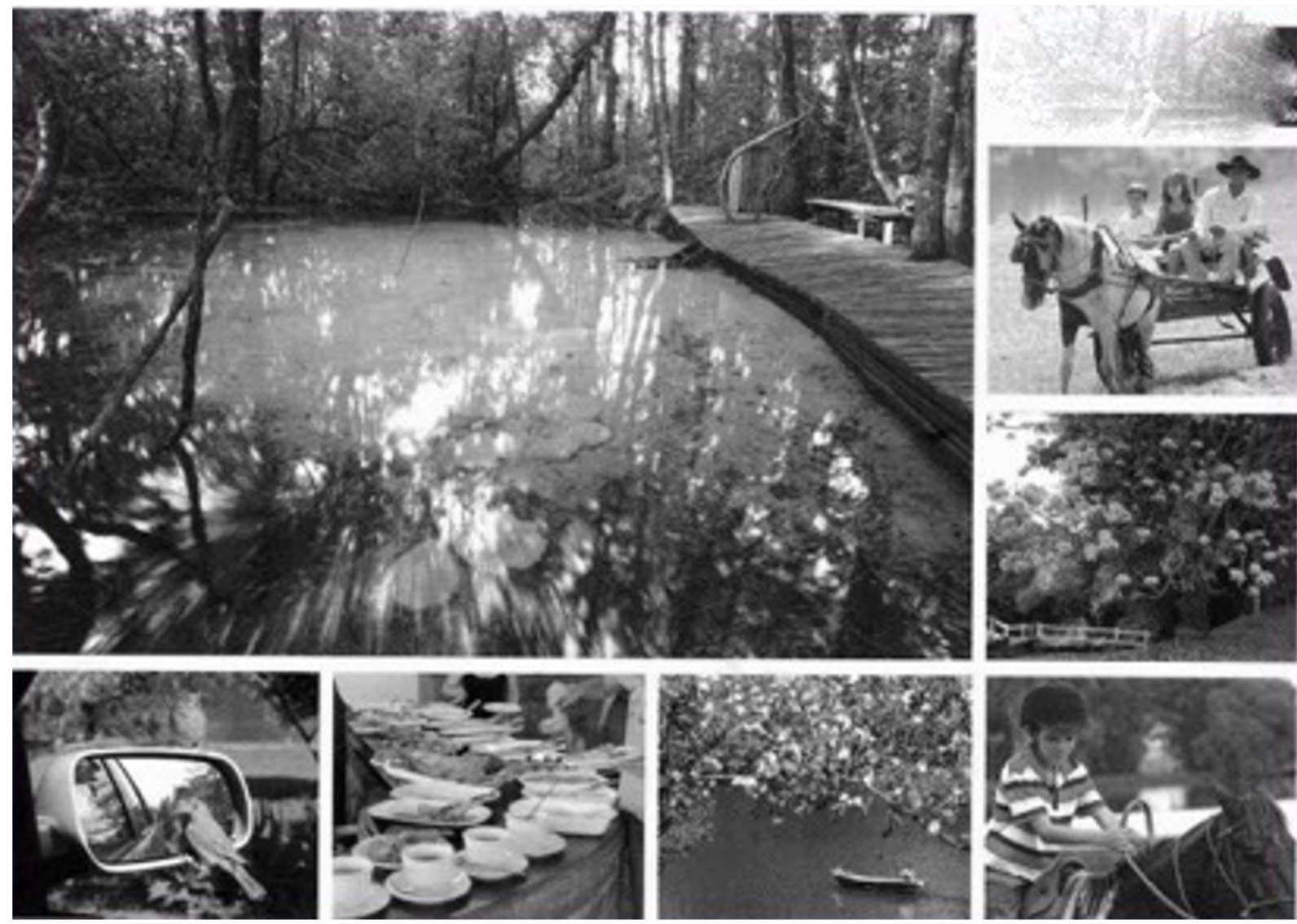

Fonte: Levantamento documental.

mais procurado pelos turistas e ponto de referência. Na imagem subsequente observa-se a hibridização de valores e de referenciais cognitivos e discursivos através de pássaros em repouso em um retrovisor de automóvel, sugerindo ao potencial consumidor dessa natureza, o turista urbano, a possibilidade de imersão em valores distintos de seu local de origem. Na sequência, nota-se uma mesa com alimentos e utensílios que evocam noções daquilo que seja campestre, idílico e campesino, ou mesmo colonial, somando-se, em seguida, à reprodução de uma lagoa e de um barco de pesca isolado. Por fim, seguem-se três fotografias sobrepostas, às quais ressaltam um ambiente seguro para as crianças e essencialmente "natural", com cavalos, charrete e com um exemplar da beleza da flora local. Toda essa densa descrição imagética sugere um rural seguro e domesticado para o lazer. A despeito de propor aventura, se oferta o controle da natureza e a profissionalização dos serviços acessórios aos atrativos ambientais, de modo a garantir segurança física e emocional do "eu".
A questão fundamental que emerge deste contexto é que o espaço rural torna-se alvo de um conjunto de imagens construídas discursivamente, o qual tende a povoar o imaginário coletivo. Verifica-se uma integração entre paisagem e território, transbordando um movimento de resgate e valorização da cultura e da sociedade local. De fato, o empreendimento turístico-rural em tela caracteriza uma geração de valor e de capital imaterial pautada na produção de signos vinculados ao arcaico, ao simples e ao rupestre, indicando uma dinâmica de reapropriação de expressões culturais (saberes e práticas) tradicionais. Assim, observa-se neste contexto uma revalorização do rural não mais como espaço de produção de bens materiais, como um sistema social (isto é, práticas sociais reproduzidas) essencialmente agrícola. Esta ruralidade é produzida por novos recursos cogniscitivos, que habilitam novas representações do espaço. Este rural pós industrial (Jollivet, 1997) torna-se uma rica fonte de bens simbólicos que, ressignificados, 
passam a alimentar uma nova dinâmica econômica, política e social de organização das relações territoriais. Se antes a propriedade que sedia o principal empreendimento turístico de Brotas possuía um conjunto de atividades econômicas baseadas na tríade agroindustrial de Brotas (eucalipto, laranja e cana-de-açúcar), nos anos 2000 esta propriedade rural adquiriu novos valores (materiais e imateriais), redefinindo seu estatuto regional para além da própria exploração econômica.

A fonte originária dessa ressignificação valorativa é de fato a natureza, que aglutina símbolos e torna-se a base de novas construções recursivas do rural na contemporaneidade. Conforme aponta a empresária:

E a gente faz tudo isso de uma forma lúdica também. Nisso tudo tem brincadeira, eles vão nesse trator e cantam. A criançada já gosta e é diferente, então não faz de conta que vai no pomar, é um pomarzão mesmo. Tem um passeio a cavalo, por exemplo, que ele vai tocar o gado. Quando a pessoa participa disso, então ela participa um pouco da lida do dia a dia. Por exemplo, tirar leite, a ordenha que a gente fala, isso é feito às nove horas da manhã. É lógico que não se ordenha vaca às nove horas da manhã, então lá tem uma, duas vacas que ficam pra isso. Agora, quem já está aqui há algum tempo, fala: "não, eu quero ver no horário", então vai levantar cinco e meia, seis horas, que é a hora que vai lá ver a ordenha de verdade. Então tudo isso a pessoa pode participar. A gente tem a horta, o pessoal vai lá, pode escolher a verdura lá, então são coisas que a gente está transformando um pouco, essa lida com rural como atividade de lazer, de recreação. E todo mundo tem uma certa ligação, sabe? Mesmo quem diz que nunca viu nada, não entende nada, não sabe comoé, mas tem lá o pai que tinha um tio que morava num sítio. (Depoimento concedido em junho de 2012)

Em síntese, há uma vinculação recursiva entre lazer, turismo, valores rurais e questão ambiental, categorias essas que não demonstram serem essenciais ou abstratas, mas eminentemente móveis e mobilizadas de acordo com a especificidade da interação social. Há a evocação de uma ligação entre natureza e cultura, entre turista e local idílico do campo, tal como expressa a informante supra: "todo mundo tem uma certa ligação". Esta ligação é recursivamente acionada como novo eixo de exploração econômica. Ademais, é a própria natureza compreendida como fator que compõe a questão ambiental que opera como estrutura social recursiva.

Nas pousadas e nos demais atrativos turísticos do município de Brotas é possível notar percepções variadas da própria noção de ruralidade, vinculadas ao objetivo de criar valor em um espaço a ser consumido por públicos turísticos variados, os quais possuem suas próprias perspectivas discursivas acerca do ambiente rural e da natureza. Assim, Brotas se nos revela um espaço caracterizado por usos plurais de seus atrativos ambientais, com movimentos planejados de ressignificação e valoração econômica dos agora "atrativos" rurais. Como define a administradora do principal empreendimento do município:

O nosso objetivo, a forma que a gente quer trabalhar é exatamente essa, valorizando as coisas da fazenda, fazendo daquilo que é uma coisa do dia a dia aqui, que não é para o turista, que aquilo seja um atrativo. E como vou transformar aquilo num atrativo? Eu faço, só para dar um exemplo, um passeio de trator, então uma carretinha, escadinha pra subir e tal, então o pessoal vai nessa carreta, tem um toldo pra ninguém tomar sol demais, tem esse passeio de trator no pomar, o pessoal vai, anda no meio do pomar, colhe laranja e os meus meninos que são da equipe adaptaram um tanque, um tanquinho de plástico, com uma torneirinha com água para a pessoa poder lavar a mão, poder lavar a laranja, então a pessoa chupa laranja no meio do pomar. (Depoimento concedido em junho de 2012)

A empresária relata exatamente a passagem de atividades rotineiras no contexto de ruralidade e que se transformam em atrativos turísticos. Esta transformação surge da própria práxis de propiciar ao turista uma experiência de imersão e de proximidade com atributos do rural, com noções subjetivas de natureza e meio ambiente. Neste caso, também há um processo de museificação da natureza, do espaço rural e de suas respectivas culturas locais, a partir do qual se observa a conservação de paisagens e objetos que deixam revelar um 'desejo urbano' de conservar o que o citadino remeteria ao rural, revelando assim - como já o fizera Williams (2011) em ensaio clássico - a força da historicidade das representações sobre a cidade e o campo.

\section{Considerações finais}

O objetivo desse artigo é discutir as transformações contemporâneas do rural a partir dos fenômenos da ressignificação da natureza e da questão ambiental. Com base na mobilização recursiva da questão ambiental, 
de seu uso como regra e recurso no âmbito do processo de ressignificação do "buraco" em atrativo turístico no município de Brotas, é mister destacar que tal arranjo está relacionado com a valoração econômica da natureza em contexto de alta modernidade, especialmente se tal valoração for identificada enquanto parte de um sistema abstrato desencaixado, capaz de influenciar dialeticamente contextos em escalas espaço-temporais diferenciadas.

A transformação do "buraco" em atrativo turístico veio acompanhada de uma verdadeira normatização das cachoeiras, dotando-as de aspectos simbólicos e materiais ancorados em conhecimentos técnicos e peritos. Os "buracos", antes aspecto problemático no âmbito da propriedade, adquiriram valor econômico e ressignificaram sua função. Antes atributo negativo, feito de repositório de materiais de toda ordem, os "buracos" foram transformados em "objetos de natureza" e em renda diferencial para os proprietários de terras. De fato, foi através destes "buracos", na condição de atrativos turísticos, que se estabeleceram as possibilidades da pluriatividade desenvolvida em torno do turismo profissional.

No plano da teoria da estruturação, é fundamental destacar como os agentes da localidade envolvidos com a propriedade da terra e com a questão ambiental operacionalizaram a estruturação recursiva de novos valores sociais a partir de ações práticas e discursivas consistentemente elaboradas. Foi no plano do agenciamento reflexivo das ações que se operou a importante ligação cognitiva entre o contexto local e os processos macrossociais. Conforme evidenciado nos resultados do estudo de caso, a competência deste agenciamento permitiu a mobilização da questão ambiental enquanto regras e recurso para a ressignificação do território local. No que tange à valoração econômica dos recursos naturais, foi relevante para a análise colocar em perspectiva a construção da narrativa em torno da mercadoria a partir da abordagem de Boltanski \& Esquerre (2017). Sem embargo, foi importante objetivar a narrativa do valor econômico, com a identificação do discurso de um metapreço - isto é, de um preço/valor que está para além da substância do trabalho (como no liberalismo clássico ou no marxismo) ou das flutuações de oferta e demanda (como no marginalismo econômico). Trata-se da justificação de práticas de mercado tacitamente aceitas pelos agentes e que, em certos contextos histórico-territoriais (ou milieu econômico específico), passam a ser recursivamente mobilizadas para a precificação dos recursos naturais E esta justificação moral, por sua vez, não deixa de trazer consigo as contradições próprias da exploração capitalista do espaço, que repercute em hierarquias e exclusões de ordens tanto material quanto simbólica.

Há, portanto, uma relação dialética entre indivíduo e sociedade, princípios estruturais e estruturas, aspectos subjetivos e objetivos, os quais fazem com que a questão ambiental seja resultado tanto das interações locais quanto daquelas interações deslocadas e desencaixadas no espaçotempo. Talvez essas características analíticas sejam as mais ricas no âmbito da teoria da estruturação, mas, ao mesmo tempo, as mais desafiadoras quando se trata da realização de uma sociologia empírica voltada ao mundo rural. Isto é, o desafio reside na apreensão das práticas sociais profundamente enraizadas na interação sociedadeambiente, que demandam novos esforços de compreensão do uso capitalista dos recursos territoriais, para além da tradicional exploração agrícola dos ecossistemas rurais.

\section{Agradecimentos}

Este estudo contou com suporte financeiro da Coordenação de Aperfeiçoamento de Pessoal de Nível Superior (Capes) e do Conselho Nacional de Desenvolvimento Científico e Tecnológico (CNPq).

\section{Referências}

Alphandéry, P., \& Billaud, J. P. (2009). Retour sur la sociologie rurale. Études Rurales, 1(183), 9-22.

Boltanski, L., \& Esquerre, A. (2017). Enrichissement: une critique de la marchandise. Paris: Gallimard.

Boltanski, L., \& Thévenot, L. (1991). De la justification: les économies de la grandeur. Paris: Gallimard.

Bourdieu, P. (2001). Meditações pascalianas. Rio de Janeiro: Bertrand Brasil.

Brandenburg, A. (2010). Do rural tradicional ao rural socioambiental. Ambiente \& Sociedade, 13(2), 417-428.

Brotas. Prefeitura Municipal. (2011). Plano municipal de desenvolvimento rural sustentável - 2010-2013 (mimeo). Brotas: Prefeitura Municipal de Brotas.

Carneiro, M. J., \& Teixeira, V. L. (2012). De terra de plantação à terra de lazer. In M. J. Carneiro (Coord.), 
Ruralidades contemporâneas: modos de viver e pensar o rural na sociedade brasileira (pp. 67-101). Rio de Janeiro: Mauad X.

Carneiro, M. J. (2008). "Rural" como categoria de pensamento. Ruris, 2(1), 9-38.

Carneiro, M. J. (2012). "Rural" como categoria de pensamento e como categoria analítica. In: Carneiro, M. J. (coord.). Ruralidades contemporâneas: modos de viver e pensar o rural na sociedade brasileira (pp. 23-50). Rio de Janeiro: Mauad X.

Dieguez-Castrillon, M. I., Gueiminde-Canto, A., SindeCantorna, A., Blanco-Cerradelo, L. (2012). Turismo rural, empreendedorismo e gênero: um estudo de caso na comunidade autônoma da Galiza. Revista de Economia e Sociologia Rural, 50(2), 371-381.

Ellis, F. (2000). Rural livelihoods and diversity in developing countries. Oxford: Oxford University Press.

Giddens, A. (1989). A constituição da sociedade. São Paulo: Martins Fontes.

Giddens, A. (2009). The politics of climate change. Cambridge: Polity Press.

Giddens, A. (2002). Modernidade e identidade. Rio de Janeiro: Jorge Zahar Editor.

Jean, B. (1997). Territoires d'avenir - Pour une sociologie de la ruralité. Sainte-Foy: Press de 1'Université du Quebec.

Jean, B. (2002). Les territoires ruraux dans la modernité avancée et la recomposition des sistèmes ruraux. Estudos Sociedade e Agricultura, vol.10 (18), 5-27.

Jollivet, M. A (1998, novembro). "Vocação atual" da sociologia rural. Estudos Sociedade e Agricultura, 10(1), 05-25.

Jollivet, M. (1997). Vers un rural posindustriel: rural et environnement dans huit pays européens. Paris: L'Harmattan.

Kayser, B. (1989). La renaissence rurale: sociologie des campagnes du monde occidental. Paris: Armand Colin.

Lafaye, C., \& Thévenot, L. (1993). Une justification écologique? Conflits dans l'aménagement de la nature. Revue Française de Sociologie, 34(4), 495-524.

Lenzi, C. L. (2006). Para uma imaginação sociológica da ecologia: uma análise do pensamento de Anthony Giddens. Ambiente \& Sociedade, IX(1), 105-128.

Long, N., \& Ploeg, J. D. (2011). Heterogeneidade, ator e estrutura: a construção da autonomia e da diversidade. In S. Schneider, \& M. Gazolla (Orgs.), Os atores do desenvolvimento rural: perspectivas teóricas e práticas sociais (pp. 21-48). Porto Alegre: Editora da UFRGS.

Lunardi, R., \& Souza, M. (2011). Turismo e inovação no meio rural: visões a partir do turismo rural na região dos Campos de Cima da Serra. In S. Schneider, \& M. Gazolla (Orgs.), Os atores do desenvolvimento rural: perspectivas teóricas e práticas sociais (pp. 221-234). Porto Alegre: Editora da UFRGS.

Madureira, G. A. (2013). A ressignificação da questão ambiental em contexto de ruralidade: para uma leitura crítica do paradoxo de Giddens (Dissertação de mestrado). São Carlos: PPGS-UFSCar.

Martins, R. C. (2005). Ruralidade e regulação ambiental: notas para um debate político-institucional. Revista de Economia e Sociologia Rural, 43(2), 249-266.

Martins, R. C. (2011). O paradoxo de Giddens. Contemporânea Revista de Sociologia da Ufscar, 1(1), 237-243.

Martins, R. C. (2014). (Novas) ruralidades e teoria social: um olhar weberiano sobre a noção de território. In R. C. Martins (Org.), Ruralidades, trabalho e meio ambiente: diálogos sobre sociabilidades rurais contemporâneas (pp. 77-95). São Carlos: EdUFSCar.

Martins, R. C. (2015). A classificação disciplinar no mercado dos enunciados ambientais. Revista Brasileira de Ciências Sociais, 30(87), 97-113.

Matilainen, A., \& Lähdesmäki, M. (2014). Nature-based tourism in private forests: stakeholder management balancing the interests of entrepreneurs and forest owners? Journal of Rural Studies, 35, 70-79.

Mcareaveu, R., \& Mcdonagh, J. (2011). Sustainable rural tourism: lessons for rural development. Sociologia Ruralis, 51(2), 175-194.

Patton, M. Q. (2002). Qualitative research and evaluation methods (3th ed.). London: Sage Publications.

Rodrigues, C. G. O. (2012). O turismo e a reconstrução do espaço rural. In M. J. Carneiro (Coord.), Ruralidades contemporâneas: modos de viver e pensar o rural na sociedade brasileira (pp. 227-246). Rio de Janeiro: Mauad X.

São Paulo. Governo do Estado. (n. d.). Turismo em São Paulo. Embratur.

Silva, L., \& Leal, J. (2015). Rural tourism and national identity building in contemporary Europe: evidence from Portugal. Journal of Rural Studies, 38, 109-119.

Weber, M. (1982). Capitalismo e sociedade rural na Alemanha. In M. Weber. Ensaios de sociologia (pp. 413-437, 5. ed.). Rio de Janeiro: Jorge Zahar Editor.

Williams, R. (2011). El campo y la cidad. Buenos Aires: Paidós.

Wright, W., \& Annes, A. (2014). Farm women and agritourism: representing a new rurality. Sociologia Ruralis, 54(4), 477-499. 